\title{
Ecologia de plântulas de Pithecolobium racemosum Ducke. 2 - 0 Comportamento populacional de plântulas (1)
}

\author{
Angela M. C. Leite ${ }^{(2)}$ \\ Judy M. Rankin $\left({ }^{2}\right)$ \\ Eduardo Lleras $\left(^{2}\right)$
}

\begin{abstract}
Resumo
Foi observado que o crescimento populacional de plântulas de Pithecolobium racemosum ocorria segundo uma curva em forma de $\mathrm{J}$ reverso, atípica, a qual foi explicada com bases na bienalidade da espécie e no rápido crescimento inicial das plântulas. Verificouse também um comportamento de crescimento populacional semelhante ao da maioria das espécies de árvores da floresta tropical, além de constatar-se uma ocorrência rara ou ocasional de adultos e plântulas na floresta primária e um acentuado incremento populacional, segundo as diferentes intensidades de perturbação. 0 crescimento individual das plântulas confirma a dependência desta espécie pela luz, colocando-a na categoria de "não tolerante". Também foi constatada a influência do raleamento na sobrevivência dos regenerantes e a influência dos adultos parentais (árvores-matrizes) sobre os mesmos. As áreas perturbadas mostram um comportamento populacional (comportamento extrínseco) semelhante quanto à freqüência de indivíduos, natalidade e baixo crescimento individual das plântulas. Entretanto, pode dizer-se que o comportamento da espécie em si (comportamento intrínseco) foi semelhante para todas as áreas, independente dos graus de raleamento, em que a maioria das plântulas crescia abaixo da média e somente algumas plântulas cresciam acima desta. Neste estudo $\mathbf{P}$. racemosum foi sugerida como espécie de enriquecimento de áreas de mata de terra firme, onde a retirada de determinadas espécies de interesse induz à formação de clareiras e possibilita o desenvolvimento das plântulas de $\mathbf{P}$. racemosum.
\end{abstract}

\section{INTRODUÇÃo}

Além dos mecanismos propriamente de estabelecimento inicial das plântulas, os quais são discutidos em trabalhos anteriores (Leite \& Rankin, 1981 a,b,c), é necessário estudar os fenômenos que regem o comportamento da população (como a natalidade, o crescimento $e$ a mortalidade), determinando se esta se encontra em equilíbrio, redução ou expansão.

Para o estudo das populações vegetais, a forma de reprodução das espécies é o ponto básico do processo de formação populacional Assim $́$ que a renologia, ou mais precisamente a época de frutificação, que implica na propagação de sementes e conseqüente natalidacie de plântulas, associada à estação chuvosa ou seca (Williams, 1941; Smith, 1970), vai contribuir para a maior ou menor sobrevivência dos regenerantes de cada espécie bem como ao crescimento vegetativo destes (Jazen, 1967). Smith (1970) e Whitmore (1975) ressaltam ainda que, a forma de dispersão de sementes pode ser mais importante para espécies de árvores, sendo que elas dependem, para sua sobrevivência, da rapidez, com a qual elas podem colonizar solos descobertos em partes na floresta adulta. Além disso, a oportuniciade de crescimento das plântulas em direta competição com seus parentes e com outras plântulas, é reduzida pela dispersão com o risco de extinção da população por pestes ou catástrofes naturais (Ridley, 1930).

É importante lembrar que não só a espécie em si determina o seu próprio comportamento; esta está estritamente associada ao ambiente ou cos diferentes ambientes nos quais determinadas espécies podem ocorrer. Portanto, se o ambiente varia, a tendêncis da população é variar em diferentes sentidos, em redução ou expansâo, dependendo do seu comportamento (cf. Odum, 1972). Variações ambientais naturais ou induzidas em áreas de mata (como, por exemplo, a formação de clareiras) induzem diferentes respostas sobre os regenerantes de

(1) - Parte da tese apresentada ao Curso de Pós-Graduação da FUA/INPA em 04-02-80, para obtenção do título de Mestre pela primeira autora.

(2) - Instituto Nacional de Pesquísas da Amazônia Manaus. 
cada espécie existente no local (Richards. 1952), alguns dos quais tendem a incrementar o crescimento vegetativo, como no caso das espécies de mata colonizadoras de clareiras ou espécies intolerantes (Richards, 1952; Schulz, 1960; Whitmore, 1975 e Pires, 1976), e outros tendem a extingüir-se dada a alteração do ambiente, como no caso das espécies altamen. te restritas à sumbra. Além disso, o tamanho das clareiras também tem influência na forma de regeneração da mata natural (Schulz, 1960; Whitmore, 1975).

Todos estes fatores referidos, contribuem para o comportamento populacional característico para cada espécie ou grupos de espécies, o que faz com que o estudo da população dos regenerantes de espécies da floresta tropical venha tendo mais importância para a ecologia e manejo florestal.

Assim, no intuito de se contribuir para o conhecimcnto ecológico florestai na região amazônica, foi feito este estudo que aborda o comp̣ortamento da população de plântulas de uma espécie tipicamente amazônica (Pithecolobium racemosum Ducke - Angelim raja. do"), visando também a elucidar alcuns dos mecenismos básicos do processo da dinâmica populacional envolvitos no estabelecimento das plânitulas da mesma.

\section{METODOLOGIA}

Este estudo foi realizado na Reserva Florestal Ducke (Rodovia AM-10, Km 26; Manaus. Itaccatiara), em sete diferentes áreas com graus de perturbação variados (Tab. I), e em áreas de mata não perturbada, anotada anteriormente por Leite \& Rankin (1981 a). Para - levantamento das plântulas de Pithecolobium racemosum, foram feitos trarisectos em cada área, sendo que o primeiro levantamento foi realizado em 1977. Em 1979 (18 meses depoisj, somente alguns destes transectos foram refeitos (alguns da área $\mathrm{I}$ e os das áreas I! III e VII), repetindo-se o mapeamento das plântulas, tomando-se em consideração as novas plântulas que surgiam por germinação de sementes (plântulas com até $15 \mathrm{~cm}$ de altura) ou por rebrotamento (com mais de $15 \mathrm{~cm}$ de altura) .
TABELA 1 - Informações sumárias sobre as áreas estudadas.

\begin{tabular}{|c|c|c|}
\hline Área & $\begin{array}{l}\text { Grau } \\
\text { Pert. }\end{array}$ & Fisionomia Ambiental \\
\hline i & 7 & $\begin{array}{l}\text { clareira grande com enriquecimento } \\
\text { florestal }\end{array}$ \\
\hline II & 2 & mata próxima à área $\mathrm{I}$ \\
\hline III & 3 & clareira pequena \\
\hline * IV & 6 & regeneração de clareira com plantio \\
\hline * V & 5 & mata em processo de regeneração \\
\hline$=\mathrm{VI}$ & 4 & regeneração de clareira sem plantio \\
\hline VII & 1 & mata sem perturbação \\
\hline
\end{tabular}

* Áreas não revisadas para este estudo.

Cada individuo foi reconhecido no ano seguinte pela posição que assumia no transecto anterior, já que não foi feita marcaçãc individual nas áreas de estudo. No entanto, o recc. nhecimento de cada plântula foi possível dado o fato de as estacas terem jermanecido nos locais, delimitando cada transecto.

Neste trabalho, para as observações do comportamento populacional das plântulas, foram utilizados somente os transectos levantados tanto em 1977 quanto em 1979. Enquanto isso, para efeitos de comparação de subáreas dos transectos, considerou-se áreas próximas aos adultos, aquelas que, dentro do transecto, atingiam o tamanho do raio da copa, e distantes, aquelas cujas áreas não eram atingidas pelas copas dos adultos parentais dos transectos. Somente os transectos, da árvore 1 à 2 , da 2 à 3 e da árvore 6 à área raleada tiveram áreas próximas e distantes dos adultos, sendo que os demais transectos apresentavam as copas dos aduitos parentais em todas as suas extensões.

Considerou-se, neste estudo, subpopulação como o conjunto de plântulas localizadas nas áreas de estudo, sem levar em conta os indivíduos adultos da mesrria espécie e as trocas gênicas entre eles.

\section{RESUltadOS OBTIDOS}

Segundo foi mencionado em trabalho anterior (Leite \& Kankin, 1981 a), o número de plântulas de Pithecolobium racemosum foi ba. 
sicamente idêntico nos dois levantamentos feitos (1977 e 1979) e a distribuição das plântulas foi do tipc agregado para todas as áreas e nos dois levantamentos consideraods, sendo as agregações maiores quanto maior a intensidade de perturbação; além disso, houve uma tendência dos regenerantes a se disporem mais às proximidades das árvores-matrizes (Fig. 1), onde se verificou o diomínio da copa dos indivíduos adultos desta espécie sobre suas plântulas, do que longe destas. Também quanto à comparação entre áreas, deve ressaltar-se o maior número de piântulas em áreas perturbades que na mata, intacta (área VII, grau de perturbação I) ou com influência de perturbação próxima (área II, grau de perturbação 2) .

Também foi observado que as plântulas desta espécie apresentam classses de altura bem representativas (Fig. 2), as quais estão correlacionadias com as diferentes intensidades de perturbação de cada área.

Quanto ao comportamento dos regenerantes de Pithecolobium racemosum, observa-se que, ao serem agrupadas as plântulas de cada transecto em classes de 5 em $5 \mathrm{~cm}$ de altura, as classes inferiores a $30 \mathrm{~cm}$ eram em geral compostas de pequenas quantidades de indivíduos (Fig. 2), o que fazia com populacionalmente $P$. racemosum apresentasse uma curva em forma de J reverso atípica, fato este que ocorreu nos dois levantamentos (1977 e 1979) Também, ao comparar-se o número de plântulas por classe de altura em cada ano, verificouse que a tendência das plântulas de mata (área VII, grau de perturbação I e área II, grau de petrurbação 2) era manterem-se basicamen. mente invariáveis na altura, enquanto que as plântulas das áreas perturbadas, variaram em classe de altura (Tab. 2). Há ainda uma tendência à homogeneização das classes de altura mais baixas predominantes e ao agrupamento das classes de altura mais baixas escassas (Fig. 2), o que pode levar a crer-se que está existindo algum fator (ou fatores), que possivelmente pode ser a luminosidade (cf. Leite \& Rankin, 1981 a), atuando em certas faixas de tamanho limitando a taxa de crescimento.
Natalidade e mortaiidade de plântulas desta espécie foram consideradas quanto à proximidade e distância das árvores-matrizes (Fig. 3) .

Para natalidade (Tab. 3), verificou-se que no transecto da árvore 6 à área raleada (área II, grau de perturbação 2), a natalidade foi sị. nificativamente maior nas proximidades do
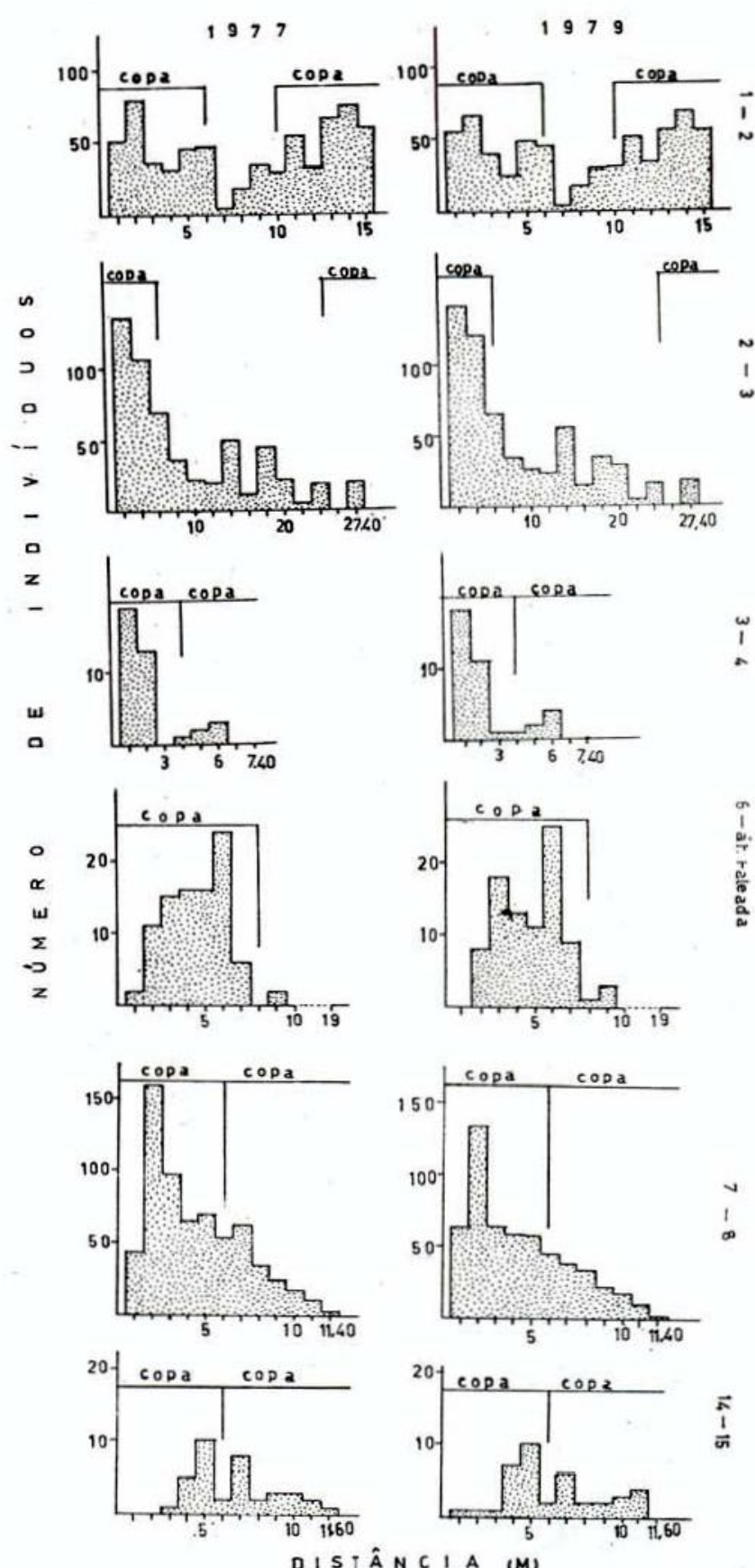

Fig. 1 - Pithecolobium racemosum. Freqüência das plântulas, segundo as distâncias entre as árvores-matrizes, nos transectos (1977 e 1979). 

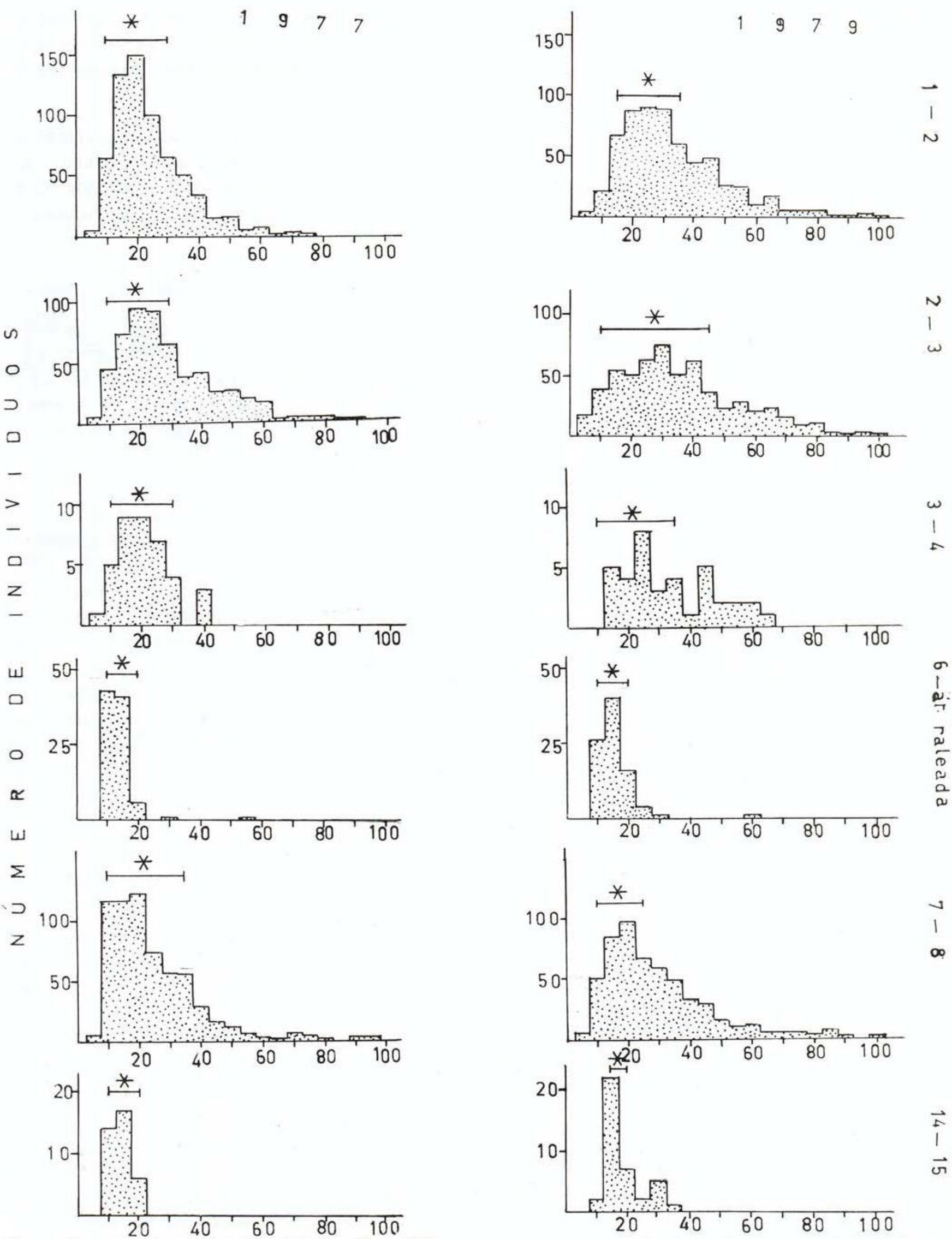

(*) - Classes de altura mais representativas. Altura (CM)

Fig. 2 - Pithecolobium racemosum. Freqüência das plân tulas, segundo as classes de altura destas, nos respectivos transectos (1977 e 1979). 
TABELA 2 - Pithecolobium racemosum. Comparação da média do número de plântulas por classe de altura entre 1977 e 1979.

\begin{tabular}{|c|c|c|c|c|c|c|c|c|c|c|}
\hline $\begin{array}{l}\text { Grau } \\
\text { Pert. }\end{array}$ & Area & Trans. & Ano & $\mathrm{N}$ & $\bar{x}$ & $\mathrm{~S}^{2}$ & $\mathrm{Fa}$ & $\mathrm{gl}$ & $\alpha \mathrm{cFb}^{\mathrm{b}}$ & sign. \\
\hline 7 & I & $1-2$ & $\begin{array}{l}1977 \\
1979\end{array}$ & $\begin{array}{l}654 \\
612\end{array}$ & $\begin{array}{l}43,6 \\
30,6\end{array}$ & $\begin{array}{l}2496,11 \\
1024,04\end{array}$ & 2,437 & $\begin{array}{l}653 \\
611\end{array}$ & 0,034 & $\cdots$ \\
\hline & & $2-3$ & $\begin{array}{l}1977 \\
1979\end{array}$ & $\begin{array}{l}551 \\
578\end{array}$ & $\begin{array}{l}30,6 \\
28,9\end{array}$ & $\begin{array}{r}1002,25 \\
543,04\end{array}$ & 1,846 & $\begin{array}{l}550 \\
577\end{array}$ & 0,099 & $\cdots$ \\
\hline & & $3-4$ & $\begin{array}{l}1977 \\
1979\end{array}$ & $\begin{array}{l}38 \\
37\end{array}$ & $\begin{array}{l}2,9 \\
2,8\end{array}$ & $\begin{array}{r}12,58 \\
5,31\end{array}$ & 2,369 & $\begin{array}{l}37 \\
36\end{array}$ & 0,005 & $\cdots$ \\
\hline 3 & III & $7-8$ & $\begin{array}{l}1977 \\
1979\end{array}$ & $\begin{array}{l}640 \\
538\end{array}$ & $\begin{array}{l}33,7 \\
28,3\end{array}$ & $\begin{array}{r}1904,34 \\
927,45\end{array}$ & 2,053 & $\begin{array}{l}639 \\
537\end{array}$ & 0,000 & $\cdots$ \\
\hline 2 & II & 6-ár.r. & $\begin{array}{l}1977 \\
1979\end{array}$ & $\begin{array}{l}93 \\
88\end{array}$ & $\begin{array}{l}8,4 \\
8,0\end{array}$ & $\begin{array}{l}286,47 \\
184,60\end{array}$ & 1,552 & $\begin{array}{l}92 \\
87\end{array}$ & 0,019 & $\bullet$ \\
\hline 1 & VII & $14-15$ & $\begin{array}{l}1977 \\
1979\end{array}$ & $\begin{array}{l}37 \\
39\end{array}$ & 9,2 & $\begin{array}{l}59,58 \\
62,25\end{array}$ & 1,045 & $\begin{array}{l}36 \\
38\end{array}$ & 0,446 & n.s. \\
\hline
\end{tabular}

a) teste de razăo de variâncias (Sokal \& Rohlf, 1969; p. 186);

b) valor crítico $\alpha / 2=0,025 ; \alpha^{c F}=$ valor calculado baseado no valor de $F$.

TABELA 3 - Pithecolobium racemosum. Natalidade e mortalidade médias de plântulas em áreas próximas e afastadas das árvores-matrizes.

\begin{tabular}{|c|c|c|c|c|c|c|c|c|c|c|c|c|c|c|c|}
\hline & $\begin{array}{l}\text { Grau } \\
\text { Pert. }\end{array}$ & Área & Trans. & Local & $\mathrm{N}$ & $\bar{x}$ & $\mathrm{~S}^{2}$ & to & $\mathrm{gl}$ & $\alpha \mathrm{ctb}^{\mathrm{b}}$ & sign. & $\mathrm{Fc}$ & $\mathrm{gl}$ & $\alpha^{\mathrm{cFd}}$ & sign. \\
\hline \multirow{6}{*}{ 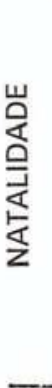 } & \multirow[t]{4}{*}{7} & \multirow{4}{*}{ I } & \multirow{2}{*}{$1-2$} & Prox. & 48 & 0,708 & 0,807 & \multirow{2}{*}{0,95} & 47 & \multirow{2}{*}{0,65} & \multirow{2}{*}{ n.s. } & \multirow{2}{*}{1,68} & 47 & \multirow{2}{*}{0,18} & \multirow{2}{*}{ n.s. } \\
\hline & & & & Dist. & 12 & 0,417 & 1,356 & & 11 & & & & 11 & & \\
\hline & & & 0 & Prox. & 44 & 0,750 & 2,099 & & 43 & & & & 43 & & \\
\hline & & & $-\quad-\quad$ & Dist. & 68 & 0,426 & 0,905 & & 67 & 0,00 & (1). & $2,0<2$ & 67 & $8,00=$ & \\
\hline & \multirow[b]{2}{*}{2} & \multirow{2}{*}{ II } & \multirow{2}{*}{ 6-ár.r. } & Prox. & 32 & 1,031 & 6,676 & \multirow[b]{2}{*}{2,20} & 31 & \multirow[b]{2}{*}{0,96} & \multirow[b]{2}{*}{ - } & \multirow[b]{2}{*}{290,26} & 31 & \multirow[b]{2}{*}{$0,1-10$} & \multirow[b]{2}{*}{$\cdots$} \\
\hline & & & & Dist. & 44 & 0,023 & 0,023 & & & & & & 43 & & \\
\hline \multirow{6}{*}{ 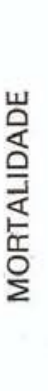 } & \multirow{4}{*}{7} & \multirow{4}{*}{ I } & \multirow{2}{*}{$1-2$} & Prox. & 48 & 2,12 & 4,28 & \multirow{2}{*}{1,77} & 47 & \multirow[b]{2}{*}{0,92} & \multirow[b]{2}{*}{ n.s. } & \multirow[b]{2}{*}{1,96} & 47 & \multirow[b]{2}{*}{0,11} & \multirow[b]{2}{*}{ n.s. } \\
\hline & & & & Dist. & 12 & 1,00 & 2,18 & & 11 & & & & 11 & & \\
\hline & & & 02 & Prox. & 44 & 0,52 & 1,09 & & 43 & & & & 43 & & \\
\hline & & & & Dist. & 68 & 0,47 & 2,13 & 0,22 & 67 & & 11.s. & (1, & 67 & 0,01 & \\
\hline & \multirow{2}{*}{2} & \multirow{2}{*}{ II } & \multirow{2}{*}{ 6-ár.r. } & Prox. & 32 & 1,19 & 2,48 & & & & & & & & \\
\hline & & & & Dist. & 76 & - & - & - & - & - & - & - & - & - & - \\
\hline
\end{tabular}

a) teste $t$ aproximado (Sokal \& Rohlf, 1969).

b) valor crítico $\alpha=0,05 ; \alpha^{\text {et }}=$ valor calculado baseado no vaior de t's.

c) teste de razão de variâncias (Sokal \& Rohlf, 1969).

d) valor crítico $\alpha / 2=0,025 ; \alpha^{\mathrm{CF}}=$ valor calculado basecdo no valor de $\mathrm{F}$. 


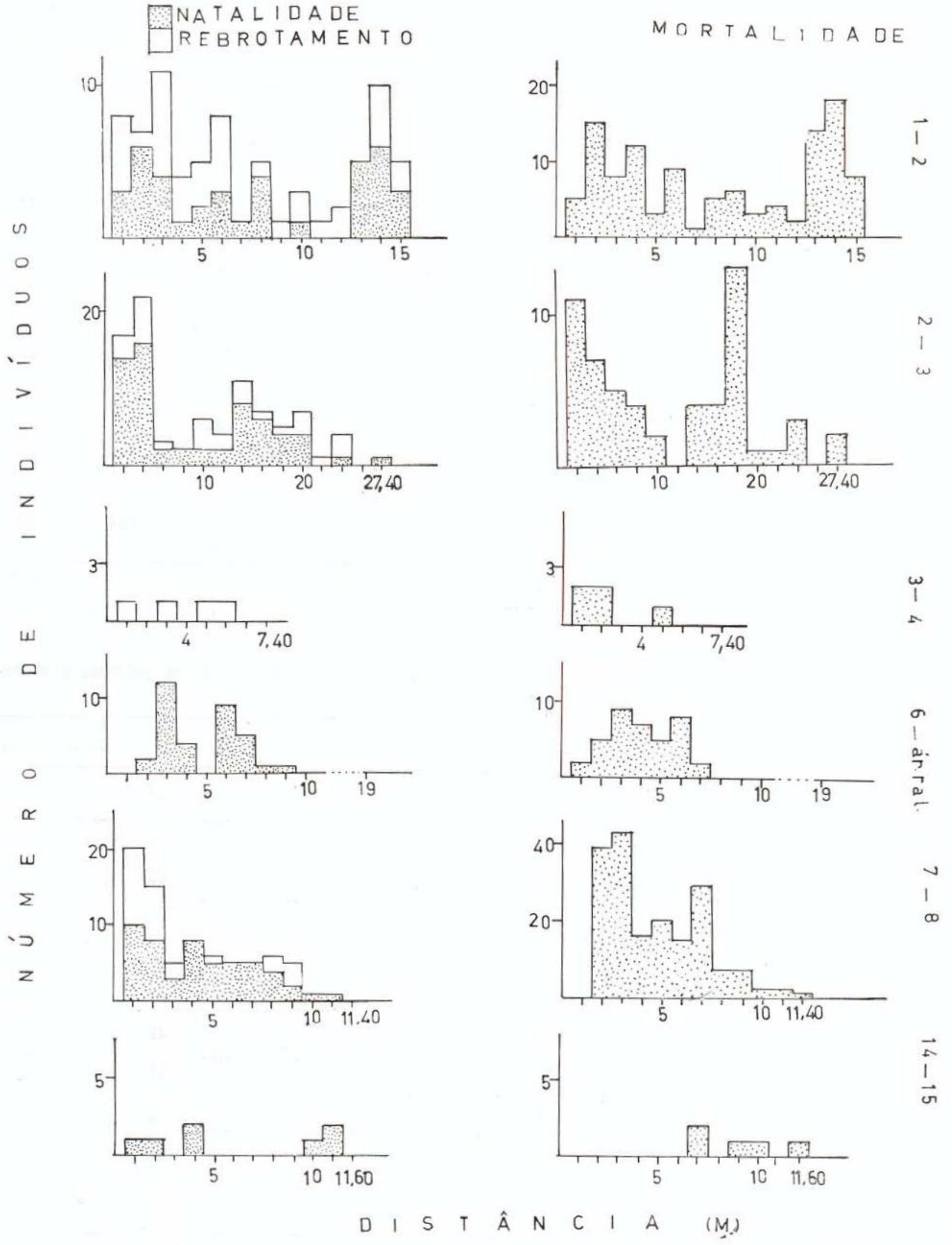

Fig. 3 - Natalidade (e robrotamento) e mortalidade de plântulas nos transectos, segundo as distâncias entre as árvores-matrizes. 
adulto parental do que longe deste, sendo este fato compatível como o maior número de indivíduos ocorrendo em volta da árvore parental. Nos outros dois transectos da área I (grau de perturbação 7), não ocorreu basicamente uma variação da natalidade no transecto da árvore 1 à 2; porém, no transecto da árvore 2 à 3 , a variância foi maior mais próximo dos adultos do que distante.

O mesmo fato encontrado para a natalidade na área I foi também verificado para a mortalidade de plântulas nestas mesmas áreas
(Tab. 3). Para a área I, a mortalidade próxima e distante das árvores-matrizes foi também idêntica à natalidade nas mesmas condições para o transecto da árvore 1 à 2, enquanto que no transecto da árvore 2 à 3 , a mortalidade ocorreu de modo inverso à natalidade, com variância maior distante do que próximo aos adultos parentais.

Pode ser observado que existe uma tendência de ocorrência maior de novos indivíduos nas áreas próximas às árvores-matrizes que longe destas, e uma tendência também de de-

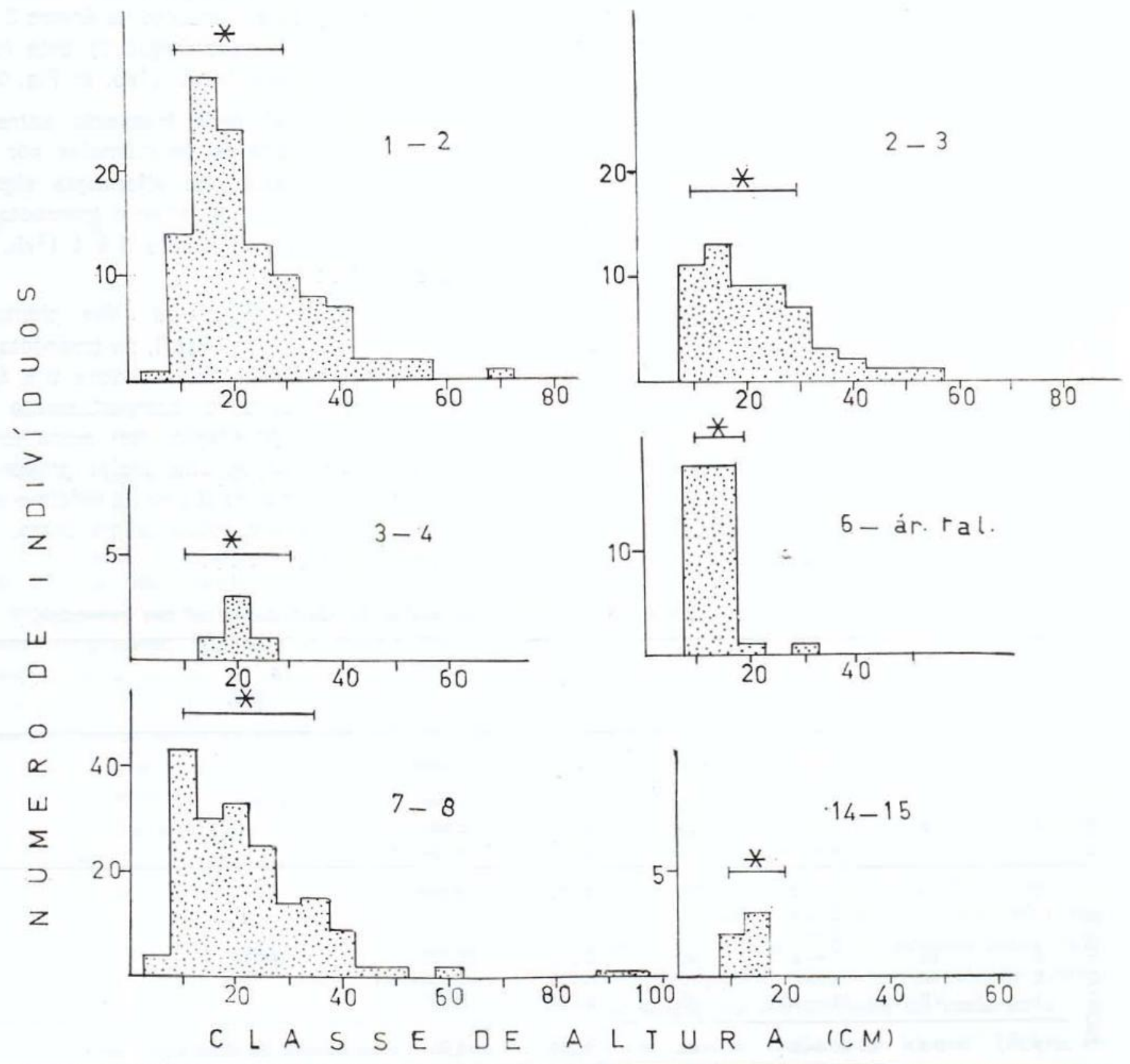

Fig. 4 - Mortalidade de plântulas segundo a classe de altura, nos transectos. 
saparecimento de plântulas !onge dos adultos parentais do que nas proxımidades deles. Fato semelhante foi observado por Fox (1977) sobre a formação de microhabitats nas proximidades dos adultos parentais, os quais proporcionam melhores condições para as plântulas.

Outro fato a ser ressaltado é a atuação mais rigorosa da mortaiidade sobre classes de altura de plântulas bem específicas (Fig. 4), estritamente relacionadas com o crescimento inicial das mesmas, a ser referido mais adiante.

A natalidade média de plântulas por $\mathrm{m}^{2}$ (Tab. 4) foi notoriamente maior na área III (grau de perturbação 3 ) do que nas demais áreas, e menor na área VII (grau de perturbação I). Por outro lado a mortalidade média de plântulas por $\mathrm{m}^{2}$ (Tab. 4) nos transectos comportou-se da mesma forma que a natalidade.

Quanto à comparação da natalidade de plântulas entre as áreas (Tab. 5), verificou-se que sempre os extremos (áreas III e/ ou área VII), em termos de perturbação, apresentavam diferenças significativas quando comparada cada uma com os demais transectos nas áreas ou entre si.

Ao comparar-se a mortalidade de plântulas entre as áreas de estudo (Tab. 6), observouse que estas diferem entre si, apresentando tendências a um aumento da mortalidade com 0 aumento do grau de raleamento.
Comparando-se ainda a natalidade com a mortalidade de plântulas por $\mathrm{m}^{2}$ para cada transecto (Tab. 7), observa-se que a tendência é de igualdade dos dois parâmetros comparados, exceto para a área III (grau de perturbação 3) e para o transecto da árvore 1 à 2 da área I (grau de perturbação 7) .

Também a regeneração cie plântulas de Pithecolobium racemosum por $\mathrm{m}^{2}$ foi conside. rada. Nos transectos das áreas I e III, nos quais há rebrotamento de algumas plântulas, encontrou-se, para a área III (grau de perturbação 3), um rebrotamento mais acentuado. enquanto que para o transecto da árvore 3 à 4 da área I (grau de perturbação 7) este fenômeno foi menos acentuado (Tab. 8; Fig. 3).

Ao comparar-se cada transecto entre si quanto ao rebrotamento de plântulas por $\mathrm{m}^{2}$. verifıcou-se não existirem diferenças signifi. cativas, exceto ao comparar-se o transecto da árvo:e 1 à 2 com o da árvore 3 à 4 (Tab. 9), ambcs na área $\mathrm{I}$.

A média de crescimento das plântulas (Tab. 10) foi maior na área $I$, no transecto da árvore 3 à 4 e menor no da árvore 6 à área raleada. No entanto, o comportamento de crescimento da população foi semelhante, constatındo-se sempre uma maior proporção da população crescendo abaixo da média e uma proporção menor crescendo acima desta, em todos os casos (Tab. II) .

TABELA 4 - Pithecolobium racemosum. Natalidade e mor talidade médias de plântulas por $\mathrm{m}^{2}$ nos transectos.

\begin{tabular}{|c|c|c|c|c|c|c|c|}
\hline & $\begin{array}{l}\text { Grau } \\
\text { Pert. }\end{array}$ & Area & Trans. & $\mathrm{N}$ & $\bar{x}$ & $\mathrm{~S}^{2}$ & $\mathrm{~F}_{\max }$ \\
\hline 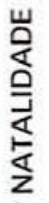 & $\begin{array}{l}7 \\
3 \\
2 \\
1\end{array}$ & $\begin{array}{r}\text { I } \\
\text { III } \\
\text { VII }\end{array}$ & $\begin{array}{c}1-2 \\
2-3 \\
7-8 \\
6 \text {-ár.r } \\
14-15\end{array}$ & $\begin{array}{r}60 \\
112 \\
48 \\
76 \\
48\end{array}$ & $\begin{array}{l}0,550 \\
0,550 \\
1,080 \\
0,447 \\
0,146\end{array}$ & $\begin{array}{l}1,380 \\
1,380 \\
1,690 \\
2,984 \\
0,166\end{array}$ & 17,976 \\
\hline 崖 & $\begin{array}{l}3 \\
2 \\
1\end{array}$ & $\begin{array}{l}I^{*} \\
\text { III } \\
\text { II } \\
\text { VII }\end{array}$ & $\begin{array}{c}1-2 \\
2-3 \\
3-4 \\
7-8 \\
6 \text {-ár.r } \\
14-15\end{array}$ & $\begin{array}{l}48 \\
76 \\
48\end{array}$ & $\begin{array}{l}0,853 \\
\\
\\
3,771 \\
0,500 \\
0,104\end{array}$ & $\begin{array}{r}2,596 \\
\\
24,885 \\
1,355 \\
0,510\end{array}$ & 48,794 \\
\hline$\Sigma$ & 7 & I & $1-2$ & 60 & 1,900 & 4,024 & $\begin{array}{l}\text { (mortalidade no transecto } 1-2 \text {, } \\
\text { sem agrupamento de dados } \mathrm{c} / \text { outros) }\end{array}$ \\
\hline
\end{tabular}

a) dados agrupados pare os transectos da área I. 
TABELA 5 - Pithecolobium racemosum. Comparação da natalidade de plântulas por $\mathbf{m}^{2}$ entre as diferentes áreas.

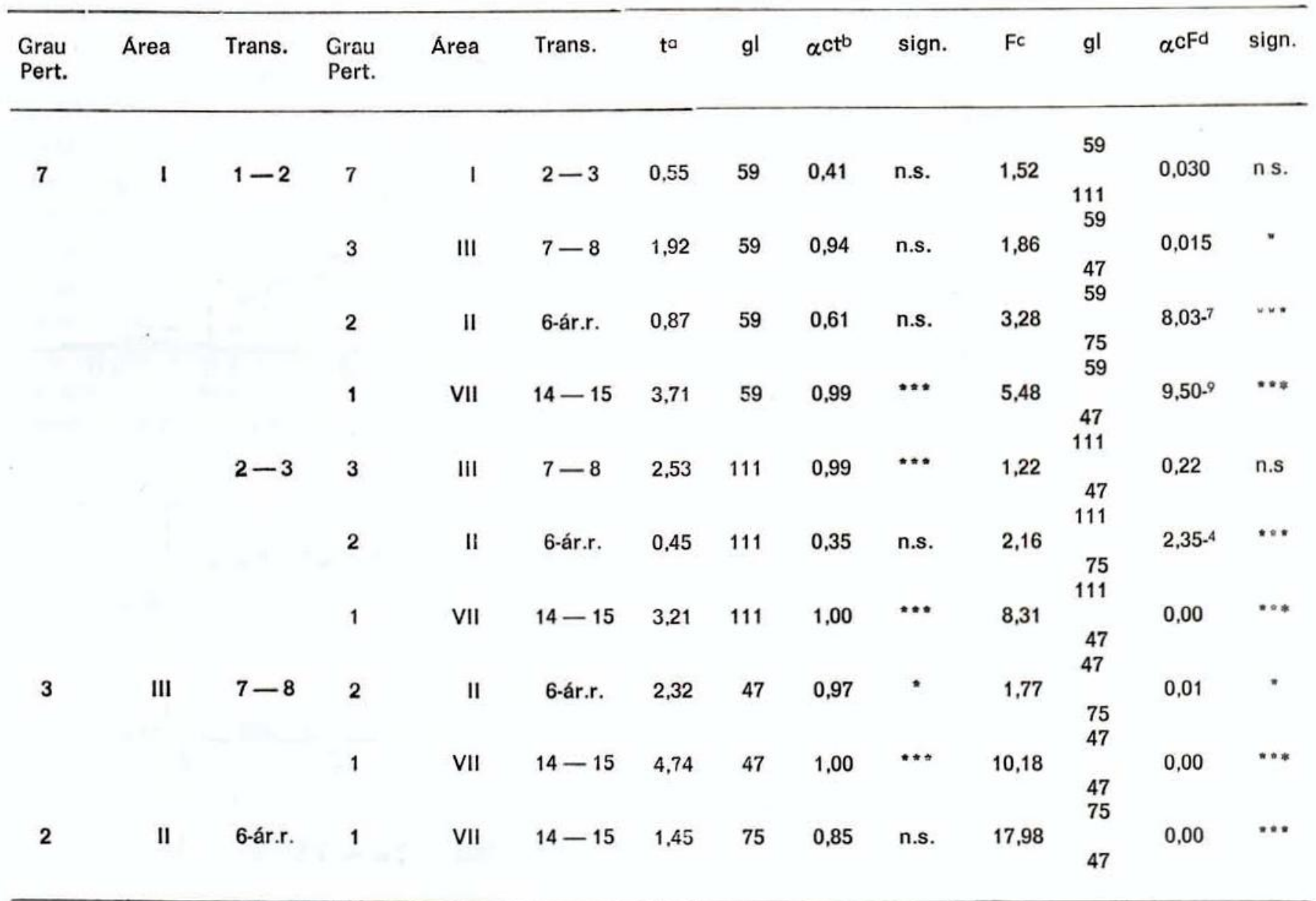

a) teste $t$ aproximado (S̄okal \& Rohlf, 1969).

b) valor critico $\alpha=0,05 ; \alpha=$ valor calculado baseado no valor de t's.

c) teste de rczão de variâncias (Sokal \& Rohlf, 1969).

d) valor crítico $\alpha / 2=0,025 ; \alpha$ cF $=$ valor cclculado beseado no valor de $F$.

Em trabalho anterior (Leite \& Rankin, $1981 \mathrm{~b})$, foi observado que as sementes de Pithecolobium racemosum, logo após a germinação, originavam, em mais ou menos uma semana, plântulas na segunda $(6-10 \mathrm{~cm})$ e na terceira $(11-15 \mathrm{~cm})$ classes de altura em área raleada. Raras eram as plântulas que ficavam na primeira classe de altura $(1-5 \mathrm{~cm})$. Em área de mata, comportamento semelhante ocorreu para as plântulas do adulto 6 de Pithecolobium racemosum, sendo que aproximadamente uma semana após a queda das sementes, as plântulas atingiram simultaneamente a segunda classe de altura. Na área VII não foi observada queda de sementes durante o período de estudo.

Os dados aqui expostos podem ser confirmados pela freqüência de novos indivíduos (pela primeira vez anotados) nas diferentes classes de altura (cf. Leite \& Rankin, 1981 a). observando-se que a primeira classe é, na. maioria dos casos, inexistente. Nas áreas onde ocorrem indivíduos na primeira classe, a freqüência dos mesmos foi sempre menor que na classe seguinte, começando a decrescer na terceira ou quarta classe de altura (Fig. 2) .

Quanto ao crescimento máximo das plântulas de $P$. racemosum, pôde observar-se (Tab. 12) que os maiores incrementos ocorreram nas áreas de mata sem perturbação ou pouco perturbadas. Observou-se também que os maiores incrementos (Tab. 12) ocorreram nas classes de altura melhor representadas (Fig. 5), s que parece ter muita currelação com a intensidade de perturbação de cada área.

Os poucos indivíduos jovens (acima de $1 \mathrm{~m}$ de altura) foram encontrados somente nas áreas perturbadas (Tab. 13) e nunca na mata 


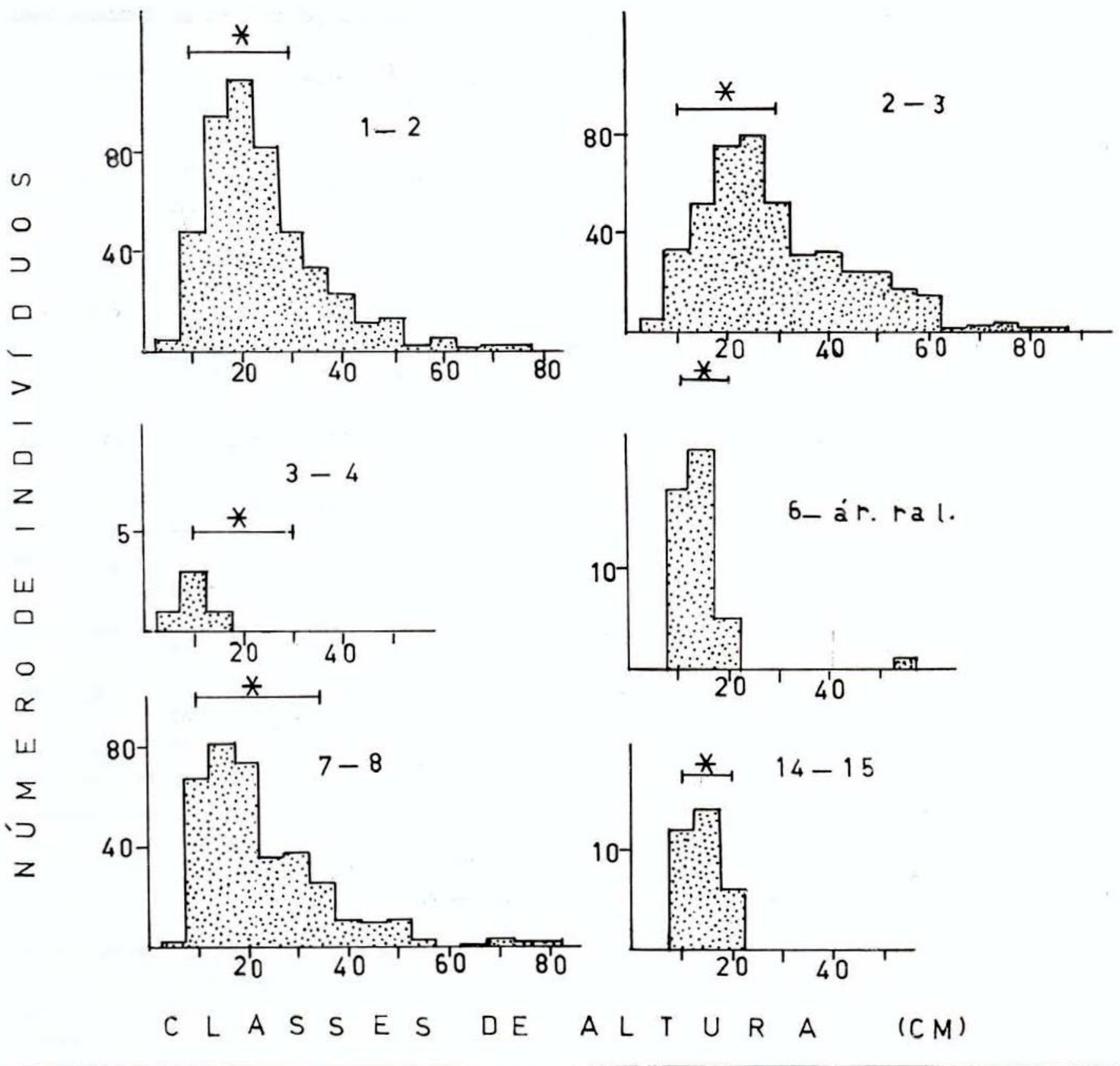

Fig. 5 - Crescimento de plântulas segundo a classe de altura, nos transectos.

primária, e tiveram um crescimento abaixo de $20 \mathrm{~cm}$. Algumas plântulas com mais de $50 \mathrm{~cm}$ cresceram entre 30 e $70 \mathrm{~cm}$ em 18 meses.

Indivíduos jovens acima de $1,30 \mathrm{~m}$ de altu. ra não foram localizados nos transectos estudados e raramente eram encontrados fora destes, sendo entretanto freqüentes na margem da estrada (que vai da Reserva Florestal Ducke ao acampamento), os quais são provenientes de germinação espontânea.

Comparando-se o crescimento de plântulas em áreas próximas e distantes dos adultos parentais (Tab. 14; Fig. 6), verificou-se que somente o transecto da árvore 1 à 2 mostrou um maior crescimento das plântulas nas áreas mais próximas dos adultos. Os outros dois transectos não mostraram diferenças significativas quanto ao crescimento próximo e distante das árvores-matrizes.

Comparando-se os transectos entre si quanto ao número de plântulas que cresciam por $\mathrm{m}^{2}$ (Tab. 15), verificou-se que, dos transectcs comparados, somente o da árvore 2 à 3 (área 1, grau de perturbação 7) comparado 
com o transecto da árvore 7 à 8 (área III, grau de perturbação 3) não mostrou diferença significativa quanto à média de plântulas cres. cencio por $\mathrm{m}^{2}$. Todos os demais transectos foram diferentes entre si quando comparados. descie o grau de significativo $(5 \%)$ até altamente significativo $(1 \%)$, com base em testes estatísticos (Tab. 15) .

Outro fato a ser ressaltado é o comportamento de crescimento semelhante nas áreas raleadas (área I, grau de perturbação 7 e área III, grau de perturbação 3), quando comparadas entre si, independente do grau de raleamento, e entre as áreas II e Vil (graus de per- u

○

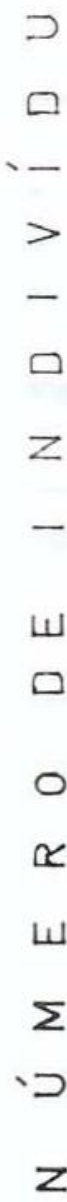
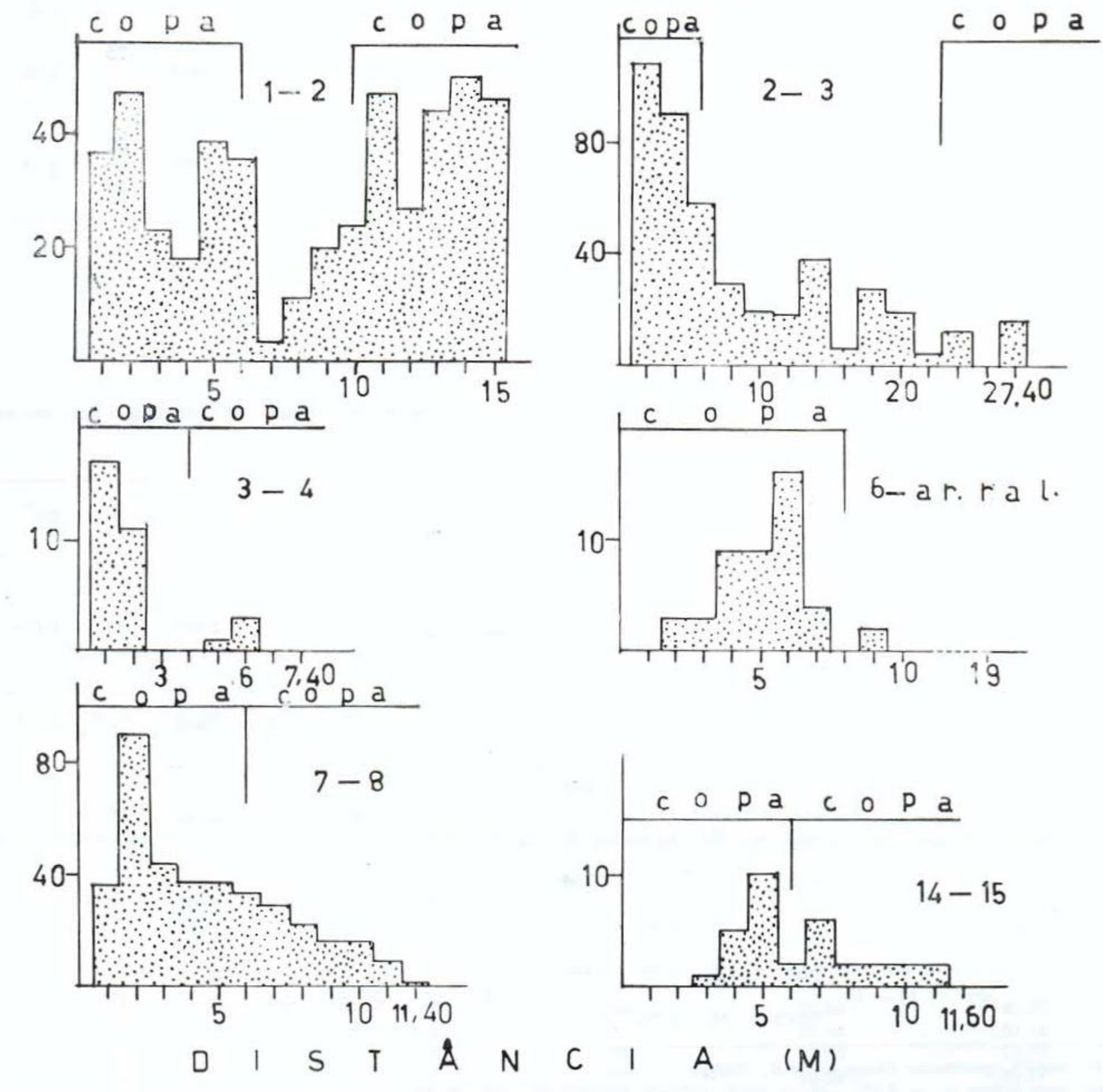

Fig. 6-Freqüência de crescimento de plântulas segundo a distância entre as árvores matrizes, nos transectos. 
TABELA 6 - Pithecolobium racemosum. Comparação da mortalidade de plântulas por $m^{2}$ entre as diferentes áreas.

\begin{tabular}{|c|c|c|c|c|c|c|c|c|c|c|c|c|c|}
\hline $\begin{array}{l}\text { Grau } \\
\text { Pert. }\end{array}$ & Area & Trans. & $\begin{array}{l}\text { Grau } \\
\text { Pert. }\end{array}$ & Áre? & Trans. & to & $\mathrm{gl}$ & $\alpha^{c t^{b}}$ & sign. & $\mathrm{Fc}$ & $\mathrm{gl}$ & $\alpha \mathrm{cFd}$ & sign. \\
\hline 1 & VII & $14-15$ & 7 & $1^{\circ}$ & $\begin{array}{l}1-2 \\
2-3\end{array}$ & 4,901 & 47 & 0,999 & $\cdots$ & 5,090 & $\begin{array}{r}47 \\
203\end{array}$ & $0,6-10$ & $\cdots *$ \\
\hline & & . & 2 & II & $\begin{array}{l}3-4 \\
\text { 6-ár.r. }\end{array}$ & 2,348 & 47 & 0,978 & $\cdots$ & 2,657 & $\begin{array}{l}47 \\
75\end{array}$ & $0,76-^{-4}$ & $\cdots$ \\
\hline 3 & III & $7-8$ & 7 & 1 & $\begin{array}{l}1-2 \\
2-3\end{array}$ & 4,004 & 47 & 0,999 & $\cdots$ & 9,586 & $\begin{array}{r}47 \\
203\end{array}$ & $0,1-10$ & 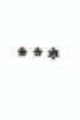 \\
\hline 2 & II & 6-ár.r. & 3 & II! & $\begin{array}{l}3-4 \\
7-8\end{array}$ & 4,467 & 75 & 0,999 & $* * *$ & 8,365 & $\begin{array}{l}75 \\
47\end{array}$ & 0,00 & $\cdots *$ \\
\hline 7 & 1 & $1-2$ & & & & 2,445 & 59 & 0,982 & $\bullet$ & 6,185 & $\begin{array}{l}59 \\
47\end{array}$ & $0,1.8$ & $* *$ \\
\hline
\end{tabular}

a) teste $t$ aproximado (Sokal \& Rohlf, 1969).

b) valor crítico $\alpha=0,05 ; \alpha=$ valor calculado baseado no valor de t's.

c) teste de razão de variâncias (Sokal \& Rohlf, 1969).

d) valor crítico $\alpha / 2=0, C 25 ; \alpha^{\mathrm{cF}}=$ valor cclculado baseado no valor de $F$.

*) dados agrupados para a área l.

TABELA 7 - Pithecolobium racemosum. Comparação entre nataiidarle e mortalidade de plântulas por $\mathrm{m}^{2}$ em cada transecto.

\begin{tabular}{|c|c|c|c|c|c|c|c|c|c|c|c|c|c|c|}
\hline $\begin{array}{l}\text { Grau } \\
\text { Pert. }\end{array}$ & Área & Trans. & Compar. & $\mathrm{N}$ & $\bar{x}$ & $\mathrm{~S}^{2}$ & ta & $\mathrm{gl}$ & $\alpha \mathrm{ctb}^{\mathrm{b}}$ & sign. & $\mathrm{Fc}$ & $\mathrm{gl}$ & $\alpha \mathrm{cFd}$ & sign. \\
\hline 7 & 1 & $1-2$ & $\begin{array}{l}\text { Nat. } \\
\text { Mort. }\end{array}$ & $\begin{array}{l}60 \\
60\end{array}$ & $\begin{array}{l}0,65 \\
1,90\end{array}$ & $\begin{array}{l}0,909 \\
4,024\end{array}$ & $4,3 \div 9$ & 59 & 0,999 & $\cdots$ & 4,427 & 59 & $2,43^{-8}$ & $\cdots *$ \\
\hline & & $2-3$ & $\begin{array}{l}\text { Nat. } \\
\text { Mort. }\end{array}$ & $\begin{array}{l}112 \\
112\end{array}$ & $\begin{array}{l}0,55 \\
0,49\end{array}$ & $\begin{array}{r}1,380 \\
1,712\end{array}$ & 0,519 & 111 & 0.395 & n.s. & 1,240 & 111 & 0,129 & n.s. \\
\hline 3 & III & $7-8$ & $\begin{array}{l}\text { Nat. } \\
\text { Mort. }\end{array}$ & $\begin{array}{l}48 \\
48\end{array}$ & $\begin{array}{l}1,08 \\
3,77\end{array}$ & $\begin{array}{r}1,690 \\
25,414\end{array}$ & 3,581 & 47 & 0,999 & $\cdots$ & 15,038 & 47 & 0,00 & $\cdots *$ \\
\hline 2 & II & 6-ár.r. & $\begin{array}{l}\text { Nat. } \\
\text { Mort. }\end{array}$ & $\begin{array}{l}76 \\
76\end{array}$ & $\begin{array}{l}0,45 \\
0,50\end{array}$ & $\begin{array}{r}2,984 \\
1,355\end{array}$ & 0,222 & 75 & 0,175 & n.s. & 2,202 & 75 & $3,84-4$ & $\cdots *$ \\
\hline 1 & VII & $14-15$ & $\begin{array}{l}\text { Nat. } \\
\text { Mort. }\end{array}$ & $\begin{array}{l}48 \\
48\end{array}$ & $\begin{array}{l}0,15 \\
0,10\end{array}$ & $\begin{array}{l}0,166 \\
0,510\end{array}$ & 0,354 & 47 & 0,275 & n.s. & 3,072 & 47 & $9,45-5$ & $\cdots$ \\
\hline
\end{tabular}

a) teste t aproximado (Sokal \& Rohlf, 1969).

b) valor critico $\alpha=0,05 ; \alpha^{\text {ct }}=$ valor calculado baseado no valor de t's.

c) teste de razão de variâncias (Sokal \& Rohlf, 1969).

d) valor crítico $\alpha / 2=0,025 ; \quad \alpha^{\mathrm{cF}}=$ valor calculado baseado no valor de $\mathrm{F}$. 
TABELA 8 - Pithecolobium racemosum. Rebrotamento de plântulas por $\mathbf{m}^{2}$ nos transectos.

\begin{tabular}{|c|c|c|c|c|c|}
\hline $\begin{array}{l}\text { Grau } \\
\text { Peit. }\end{array}$ & Area & Trans. & $\mathrm{N}$ & $\bar{x}$ & $\mathrm{~S}^{2}$ \\
\hline & & $1-2$ & 60 & 0,62 & 1,05 \\
\hline \multirow[t]{2}{*}{7} & I & $2-3$ & 112 & 0,26 & 3,20 \\
\hline & & $3-4$ & 32 & 0,12 & 0,50 \\
\hline 3 & III & $7-8$ & 48 & 0,52 & 1,57 \\
\hline
\end{tabular}

TABELA 9 - Pithecolobium racemosum. Comparação do rebrotamento de plântulas por $\mathrm{m}^{2}$ entre os transectos.

\begin{tabular}{|c|c|c|c|c|c|c|c|c|c|c|c|c|c|}
\hline $\begin{array}{l}\text { Grau } \\
\text { Pert. }\end{array}$ & Área & Trans. & $\begin{array}{l}\text { Grau } \\
\text { Pert. }\end{array}$ & Area & Trans. & $i 0$ & $\mathrm{gl}$ & $\alpha \mathrm{ct}^{\mathrm{b}}$ & sign. & $\mathrm{Fc}$ & gl & $\alpha \mathrm{cF}^{\mathrm{d}}$ & sign. \\
\hline 3 & III & $7-8$ & 7 & 1 & $1-2$ & 0,437 & 47 & 0,34 & n.s. & 1,49 & $\begin{array}{l}59 \\
47\end{array}$ & 0,08 & n.s. \\
\hline & & & & & $2-3$ & 1,050 & 47 & 0,70 & n.s. & 2,04 & $\begin{array}{r}111 \\
47\end{array}$ & 0,003 & $\cdots \theta$ \\
\hline & & & & & $3-4$ & 1,797 & 47 & 0,92 & n.s. & 3,14 & $\begin{array}{l}31 \\
47\end{array}$ & $0,06-^{2}$ & $\cdots$ \\
\hline 7 & 1 & $1-2$ & & & $2-3$ & 1,677 & 59 & 0,90 & n.s. & 3,05 & $\begin{array}{r}59 \\
111\end{array}$ & $0,21.6$ & $\cdots$ \\
\hline & & & & & $3-4$ & 2,720 & 59 & 0,99 & $\cdots$ & 2,10 & $\begin{array}{l}59 \\
31\end{array}$ & 0,013 & - \\
\hline & & $2-3$ & & & $3-4$ & 0,642 & 111 & 0,48 & n.s. & 6,40 & $\begin{array}{r}111 \\
31\end{array}$ & $6,56-8$ & $\cdots$ \\
\hline
\end{tabular}

a) teste $t$ aproximadc (Sokai \& Rohlf, 1969).

b) valor crítico $\alpha=0,05 ; \alpha^{\text {ct }}=$ valor calculado baseado no valor de t's.

c) teste de razão de variâncias (Sokal \& Rohif, 1969).

d) valor critico $\alpha / 2=0,025 ; \alpha^{\mathrm{cF}}=$ valor calculado baseado no valor de $\mathrm{F}$.

TABELA 10 - Pithecolobium racemosum. Crescimento médio de plântulas $(\mathrm{em} \mathrm{cm})$ por $\mathrm{m}^{2}$ em cada transecto.

\begin{tabular}{crrrrr}
\hline $\begin{array}{l}\text { Grau } \\
\text { Pert. }\end{array}$ & Aréa & Trans. & N & S $^{2}$ \\
\hline & & $1-2$ & 503 & 11,56 & 87.55 \\
7 & 1 & $2-3$ & 459 & 10,30 & 51.19 \\
& & $3-4$ & 32 & 13,66 & 79,07 \\
2 & III & $7-8$ & 370 & 10,09 & 86.17 \\
1 & II & 6 -ár.r. & 31 & 5,35 & 7,70 \\
\hline
\end{tabular}


TABELA 11 - Pithecolobium racemosum. Porcentagem de indivíduos crescendo em relação à média.

\begin{tabular}{|c|c|c|c|c|}
\hline $\begin{array}{l}\text { Grau } \\
\text { Pert. }\end{array}$ & Area & Trans. & $\begin{array}{l}\% \text { Cresc. } \\
\text { Acima } \bar{x}\end{array}$ & $\begin{array}{l}\% \text { Cresc. } \\
\text { Abaixo } \bar{X}\end{array}$ \\
\hline & & $1-2$ & 29,14 & 48,01 \\
\hline \multirow[t]{2}{*}{7} & 1 & $2-3$ & 33,94 & 50,63 \\
\hline & & $3-4$ & 39,47 & 44,74 \\
\hline 3 & III & $7-8$ & 23,59 & 38,91 \\
\hline 2 & II & 6-ár.r. & 27,17 & 31,52 \\
\hline 1 & VII & $14-15$ & 32,43 & 54,05 \\
\hline
\end{tabular}

TABELA 12 - Pithecolobium recemosum. Crescimento máximo de plântulas segundo a classe de altura e incremento máximo das plântulas $(\mathrm{cm})$ durante 18 meses em cada transecto.

\begin{tabular}{lcccc}
\hline $\begin{array}{l}\text { Grau } \\
\text { Pert. }\end{array}$ & Area & Trans. & $\begin{array}{c}\text { Classe de Altura } \\
\text { de Maior Crescimento } \\
\text { (CM) }\end{array}$ & $\begin{array}{c}\text { Incremento } \\
\text { Máximo } \\
\text { (CM) }\end{array}$ \\
\hline & & $1-2$ & 30 & 65 \\
2 & 1 & $2-3$ & $25-50$ & 48 \\
3 & & $3-4$ & $11-15$ & 38 \\
1 & III & $6-a$ r.r. & 30 & 70 \\
\end{tabular}

TABELA 13 - Pithecolobium racemosum. Crescimento de algumas plântulas que ultrapassaram de $1 \mathrm{~m}$ de altura, e dos Indivíduos jovens (com mais que $1 \mathrm{~m}$ de altura), que ocorreram nas áreas I e III somente.

\begin{tabular}{lcccc}
\hline $\begin{array}{l}\text { Grau } \\
\text { Pert. }\end{array}$ & Area & Trans. & $\begin{array}{c}\text { Alt. (CM) de Pls. } \\
\text { e Indivíduos Jovens } \\
\text { (1977) }\end{array}$ & $\begin{array}{c}\text { Alt. (CM) de Pls. } \\
\text { e Indivíduos Jovens }\end{array}$ \\
\hline 7 & 1 & $2-3$ & 56 & 123 \\
& & & 89 & 118 \\
& & & 76 & 113 \\
3 & & & 122 & 120 \\
\hline
\end{tabular}

TABELA 14 - Pithecolobium racemosum. Crescimento médio de plântulas em áreas próximas e distantes das árvores parentais.

\begin{tabular}{|c|c|c|c|c|c|c|c|c|c|c|c|c|c|c|}
\hline $\begin{array}{l}\text { Grau } \\
\text { Pert. }\end{array}$ & Area & Trans. & Local & $\mathrm{N}$ & $\bar{x}$ & $\mathrm{~S}^{2}$ & $n$ & gl & $\alpha \mathrm{ctb}^{b}$ & sign. & $\mathrm{Fc}$ & gl & $\alpha \mathrm{cFd}$ & sign. \\
\hline 7 & 1 & $1-2$ & $\begin{array}{l}\text { Prox. } \\
\text { Dist. }\end{array}$ & $\begin{array}{r}462 \\
41\end{array}$ & $\begin{array}{r}11,86 \\
8,15\end{array}$ & $\begin{array}{l}90,0 \\
48,5\end{array}$ & 3,15 & 461 & 0,998 & $\cdots$ & 1,85 & $\begin{array}{r}461 \\
40\end{array}$ & 0,009 & $* *$ \\
\hline & & $2-3$ & $\begin{array}{l}\text { Prox. } \\
\text { Dist. }\end{array}$ & $\begin{array}{l}278 \\
181\end{array}$ & $\begin{array}{c}10,42 \\
10,11\end{array}$ & $\begin{array}{l}48,9 \\
54,9\end{array}$ & 0,45 & 271 & 0,346 & n.s. & 1,12 & $\begin{array}{r}277 \\
180\end{array}$ & 0,198 & n.s \\
\hline 2 & II & 6-ár.r & $\begin{array}{l}\text { Prox. } \\
\text { Dist. }\end{array}$ & $\begin{array}{r}44 \\
2\end{array}$ & $\begin{array}{l}3,25 \\
5,50\end{array}$ & $\begin{array}{r}7.3 \\
24,5\end{array}$ & 1,12 & 43 & 0,733 & n.s. & 3,37 & $\begin{array}{c}43 \\
1\end{array}$ & 0,411 & n.s \\
\hline
\end{tabular}

a) teste $t$ aproximado (Sokal \& Rohlf, 1969).

b) valor critico $\alpha=c, 05 ; \alpha^{\text {ct }}=$ valor calculado baseado no valor de t's.

c) teste de razão de variâncias (Sokal \& Rohlf, 1969).

d) valor crítico $\alpha / 2=0,025 ; \alpha{ }^{c F}=$ valor calculado baseado no valor de $F$. 
TABELA 15 - Pithecolobium racemosum. Comparação do crescimento de plântulas por $\mathrm{m}^{2}$ entre as diferentes áreas.

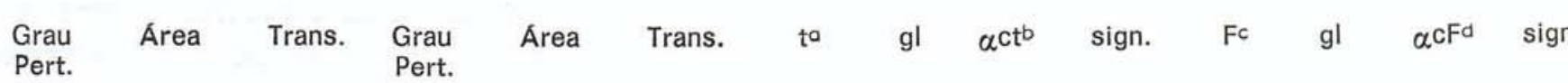

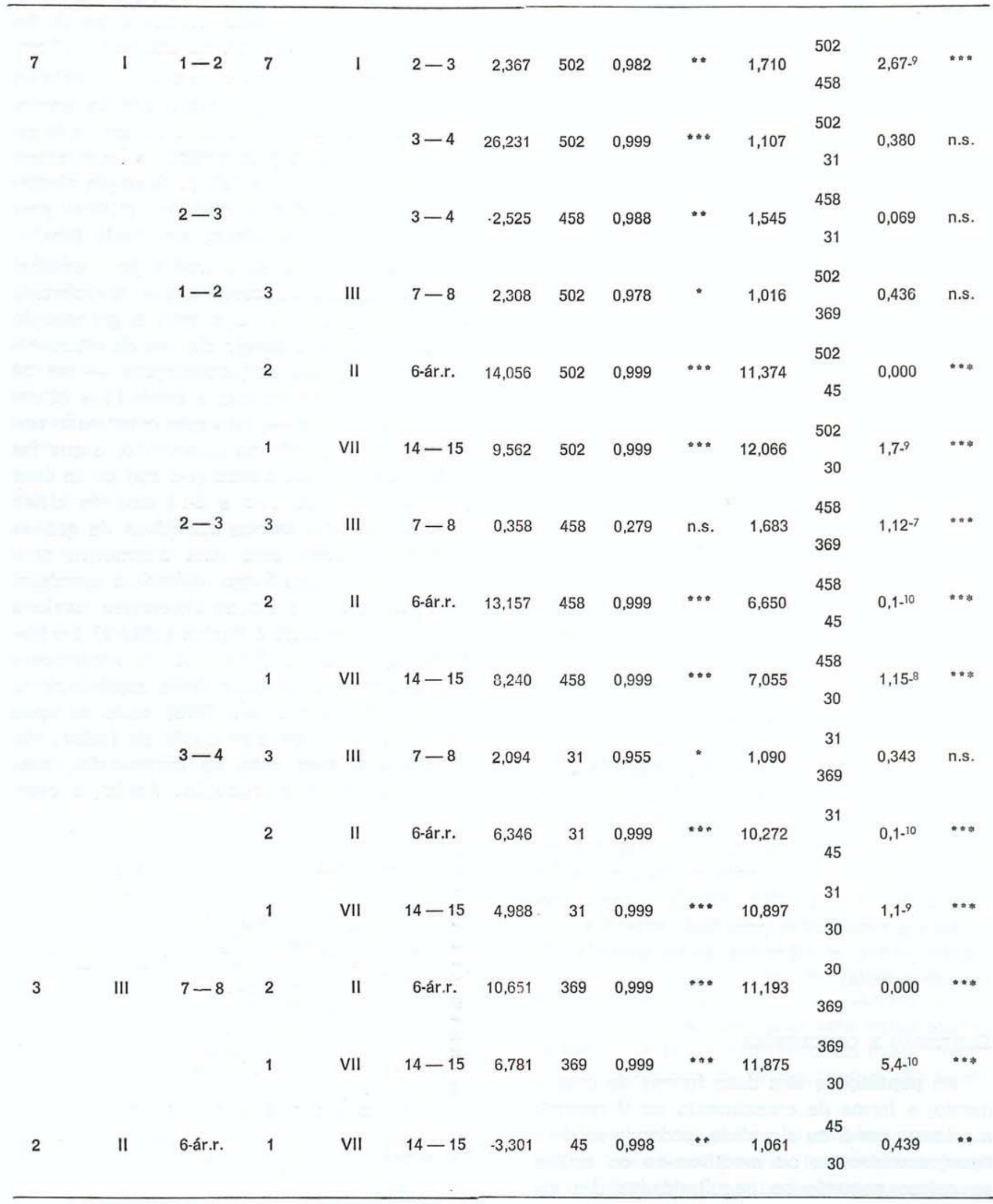




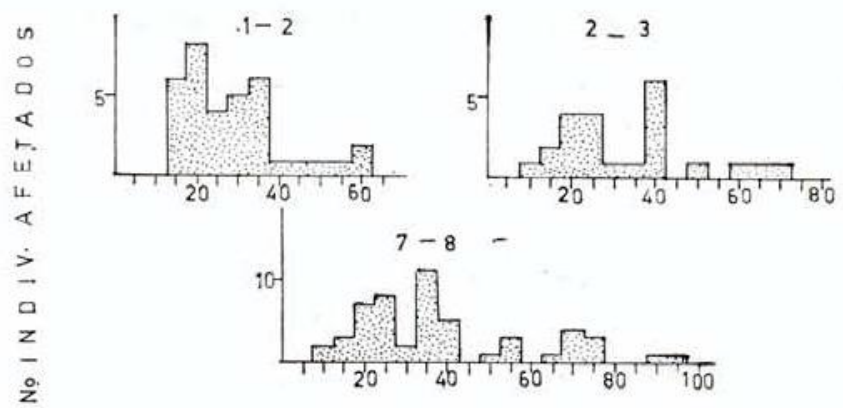

C L A.S S ES DE ALIUR A (CM)

Fig. 7 - Plântulas atetadas, segundo a classe de altura, nos transectos.

Correlacionando a classe de altura com a porcentagem de plântulas afetadas naquela classe (Fig. 7), observou-se que havia uma tendência de correlação entre os dois parâmetros. As plântulas afetadas, nos casos onde elas existiam (nos transectos referidos) mostraram tendência de comportamento semeIhante entre si, ou seja, proporções semelhantes de jlântulas afetadas segundo a classe de altura (Fig. 7) .

Equiparando-se a porcentagem de plântulas afetadas conforme a distância em metros dos adultos (Fig. 8), observou-se que nos transectos da árvore 1 à 2 e da 7 à 8 a porcentagem de plântulas afetadas não apresentava correlação com a distância. Somente no transecto da árvore 2 à 3 , a correlação foi mais evidente, sendo que a porcentagem cie plântulas afetadas era algo maior mais próximo da árvore 2 que da 3 no transecto (Fig. 8).

Outro fato observado com respeito às plântulas, foi o aumento das partes fotossintéticas, em conseqüência do aumento do número de ramos laterais (quebra da dormência das gemas laterais) causada pela perda das partes apicais da plântula. Também deve ser acrescentada a capacidade, principalmente dos indivíauos jovens e plântulas desta espécie, de resistir à poda.

\section{DISCUSSÃO E CONCLUSÕES}

As populações têm duas formas de crescimento, a forma de crescimento em J reverso e a torma em $\mathrm{S}$ ou sigmóide, podendo os dois tipos, combinar-se ou modificar-se ou ambas as coisas segundo as peculiaridades dos di- versos organismos e seus meios (Odum, 1972).

A curva em forma de $\mathrm{J}$ reverso é característica para a maioria das espécies de árvores (Baur, 1968; Daubenmire, 1974), onde a densidade aumenta exponencialmente e se detém bruscamente por resistência ambiental eficaz.

Para Pithecolobium racemosum conclui-se que o crescimento populacional ocorria, segundo uma curva em forma de $\mathrm{J}$ reverso atípica, fato este constado para ambos os levantamentos rea!izados (1977 e 1979). Situação similar foi observada por Hartshorn (1972) para Stryphnodendron excelsum, em Costa Rica.

As alternativas encontradas para explicar esta atipicidade da curva são o crescimento rápido das plântulas, logo após a germinação das sementes até atingir classes de altura es. pecíficas segundo as perturbações - até 30 $\mathrm{cm}$ em áeras perturbacias e entre 11 e $20 \mathrm{~cm}$ em áreas de mata - , fato este constatado tanto no campo quanto no laboratório, o que faz com que a primeira classe $(1-5 \mathrm{~cm})$ ou as duas primeiras classes $(1-5$ e $6-10 \mathrm{~cm})$ de altura apresentem bem menos indivíduos do que as seguintes, sendo esta uma alternativa também sugerida para Stryphnodendron excelsum (Hartshorn, 1972); a outra alternativa, também constatada por Leite \& Rankin (1981 b) é a bienalidade típica de Pithecolobium racemosum (ou a fenologia irregular desta espécie como sugerem Alencar et al., 1979) onde os anos de safra, com grande produção de frutos, são intercalados com anos de contra-safra, com pouca ou nenhuma produção. Assim, o cres-

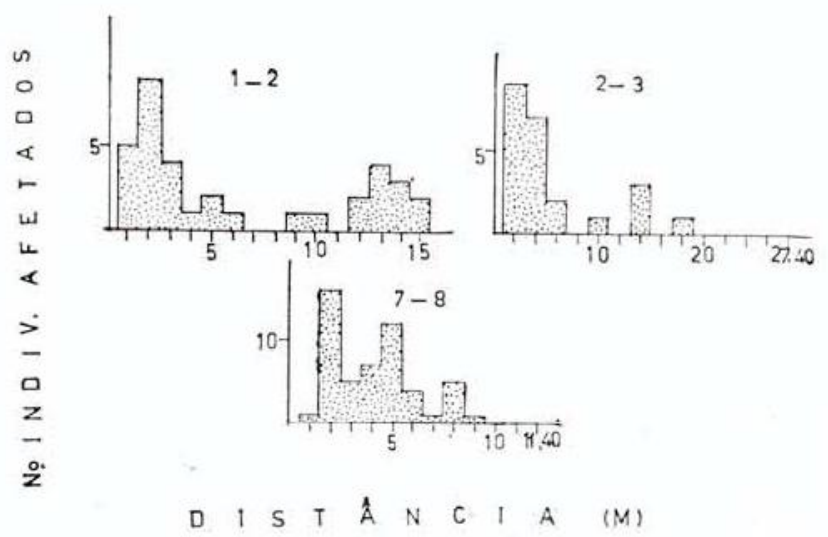

Fig. 8-Plântulas afetadas segundo a distância entre árvores-matrizes nos transectos. 
cimento rápido das plântulas logo após a germinação (crescimento inicial), a bienalidade da espécie somados ao efeito global da preda. ção de sementes (Leite \& Rankin, 1981 b) por "periquitos" (Aratinga sp.) têm forte influência sobre a dinâmica populacional de $P$. racemosum e mais especificamente sobre a natalidade e o crescimento das suas plântulas.

É possível, então, dizer que $P$. racemosum segue a regra geral de crescimento populacio. nal de árvores, agrupando-se as plântulas en: classes de $30 \mathrm{em} 30 \mathrm{~cm}$ de aitura, embora sem considerar os adultos, salientando-se a baixa freqüência de indivíduos de tamanho superior a $1 \mathrm{~m}$ e adultos na floresta.

Não é possivel agrupar as classes de altura clos indivíduos de áreas de mata face à baixa densidade populacional destes, sendo, entretanto, importante frisar que o comporta. mento dos indivíduos nestas áreas é populacionaimente semelhante ao encontrado nas áreas perturbadas, conforme o exposto nos resultados. A ocorrência rara ou ocasıonal de $P$. racemosum em mata primária é paralela à Stryphnodendiron excelsum, podendo excluir-se a hipótese de uma amostragem inadequada destas, tanto neste trabalho quanto no de Hartshorn (1972), com base nas curvas de crescimento populacional semelhantes para as duas espécies.

Por outro lado, observou-se que "na fase de plântula" $P$. racemosum é bem representada em classes de altura mais ou menos comuns, porém as diferentes intensidades de perturbação podem ampliar (no caso das mais perturbadas) ou restringir (nas menos perturbadas) a dominância das alturas das plântulas. Isto sugere que existe um limiar de altura representativo desta espécie (pelo menos para as plântulas) na floresta, conforme questiona Richards (1952) sobre o fato para os principais dominantes das florestas tropicais. É também nessas classes de altura mais representativas que se pode observar o maior dinamismo populacional das plântulas de $P$. racemosum (evidente em natalidade, mortalidade e crescimento), tanto nas clareiras quanto nas áreas de mata.

A maior quantidade de luz como efeito do raleamento, pocie induzir um maior crescimen- to das plântulas (Baur, 1964; Schulz, 1960; Whitmore. 1977 e Fox, 1973; cit. Rankin, 1972). Em condições de floresta primária intacta, o sombreamento da copa exerce uma função inibidora sobre o crescimento das plântulas de muitas espécies características da mata, as quais somente conseguem crescer pela forma ção de clareiras (Richards, 1952). O observado para Pithecolobium racemosum foi o aumento em altura das plântulas, maior em áreas raleadas do que nas menos perturbadas ou intactas, confirmando a dependência da espécie pela luz. A mesma dependência pela luz foi encontrada por Lamb (1966) para plântulas de Swietenia macrophylla, "mogno", na América Central e do Sul.

Schmidt \& Volpato (1972), em plantio experimental de algumas mudas de espécies florestais na Reserva Florestal Ducke, observaram que $P$. racemosum, em um período de 6 anos, cresceu entre 3,50 e $5,00 \mathrm{~m}$, menos porém que Carapa guiariensis ("andiroba"), Dipiotropis sp. ("sucupira"), Calophyllum brasilense ("jacareúba"), Terminalia tanimbouca ("cuiarana grande"), Coumarouna odorata ("cumaru") e scleronema micranthum ("cardeiro verdadeiro"), espécies que apresenta. ram um melhor desenvolvimento na área dos experimentos.

0 crescimento dos indivíduos jovens nas áreas raleadas (clareiras), oncie permaneciam representantes adultos da mata anteriormente existente no local, não ultrapassou $20 \mathrm{~cm}$, conforme o exposto anteriormente. É possível que, nestas áreas, as árvores que aí permaneceram estejam reduzindo a luz que chega à parte inferior tia floresta (ct. Hett \& Loucks. 1971) inibindo o crescimento, enquanto que na área de plantio experimental, a mata foi totalmente derrubada e as espécies foram plantadas em condições de plena luminosidade, com sombreamento apenas parcial de Cecropia sp , retirado 4 anos após o plantio (Schmidt \& Volpato, 1972). Até que ponto este sombreamerto parcial pode ter suprimido um maior crescimento de Pithecolobium racemosum não é este conhecido.

O raleamento pode não só afetar o crescimento como parece influir também na sobrevivência das plântulas e pode estar correlaciona- 
da com o "stress" causado pela copa que reduz a iuz e a queda de água (Hett \& Loucks, 1971). Miles (1973), comparando a mortalidade precoce de plântulas de estágios iniciais de sucessão na Zona Temperada, em sete locais perturbados, encontrou mortalidade de 1/10 daquela em áreas não perturbadas.

Para Pithecolobium racemosum, observouse que o estabelecimento de plântulas nas áreas raleadas era maior do que na mata, e que a mortalidade, além de estar correlacionada espacialmente com o grau de perturbação, foi evidenciada em todas as faixas de altura (nas diferentes áreas), o que coincide com o postulado de Harper (1967) para todas as populações de plantas, e foi mais rigorosa nas classes subseqüentes às atingidas pelo crescimento inicial oriundo da germinação das sementes. Sobre o fato da atuação da mortalidade nas espécies da floresta, Richards (1952) questiona: em que estágios a forte mortalidade (e então a seleção natural mais intensa) ocorre?. Pode dizer-se que em $P$. racemosum (especificamente no estágio de plântulas), a mortalidade (ou seleção natural ?) atua mais fortemente em estágios específicos, aparentemente relacionados com o comportamento intrínseco da espécie. Por outro lado, a alta variabilidade na mortalidade pode ser atribuída ao processo de competição hierárquica (Harper, 1978), que resulta em poucos indivíduos supressores e muitos indivíduos fracos reprimidos (por competição pela luz), espalhados ao longo dos transectos.

Em trabalho anterior (Leite \& Rankin, 1981 a), foi mencionado que a densidade de plâniulas era maior nas proximidades dos adul. tos (árvores-matrizes). Para explicar esta densidade maior nestas subáreas, pode basear-se primeiramente no tipo de dispersão de sementes, autocórica, segundo a classificação de Van der Pijl (1972), com tendência a cair nas proxımidades clos adultos reprodutores (Leite \& Rankin, 1981 b) .

Schulz (1960) menciona que a distribuição em mosaico des indivíduos jovens de muitas espécies (os quais freqüentemente estão concentrados próximos às árvores-matrizes) é possivelmente a causa direta da distribuição agregada, mostrada pelos adultos tanto dos estratos superiores quanto dos inferiores, na floresta. Também foi observado que a taxa de natalidade era maior sob as copas das árvoresmatrizes do que longe do domínio delas, e que existia uma tendência de a mortalidade ser menor sob a copa dos parentais do que distante. É possível que esta distribuição, associada com os indices de natalidade e mortalidade, seja atribuída à "chance de regeneração" assim denominade por Van Steenis (1958; cit. Schulz, 1960). Isto parece indicar que existe uma melhor condição de scbrevivência de plântulas quanto mais próximas aos adultos e esta observação coincide com o postulado por Fox (1977) quanto à formação de microhabitats para plântulas nas proximidades dos adulios parentais, os quais reduzem a perda de regenerantes e permitem que, no caso de morte do adulto próximo, uma ou algumas plântulas possam substituí-lo no inesmo local (cf. Janzen, 1970) .

No caso de compararem-se os transectos entre si, por exemplo, quanto à natalidade de plântulas por $\mathrm{m}^{2}$, observa-se uma certa tendência de comportamento semelhante para as áreas perturbadas ( $\mathrm{l}$ e III) e para as pouco ou não perturbadas (II e VII). As áreas perturbadas são semelhantes entre si quanto a este parâmetro do mesmo modo quie as de mata e as pouco perturbadas também tendem a ser equivalentes quanto ao número de plântulas que nascem por $\mathrm{m}^{2}$. Esta natalidade, entretanto, parece estar também correlacionada com o grau de perturbação e indiretamente com a disponibilidade de luz, a quai permite que es. tas plântulas possam desenvolver-se até determinados limites de altura, dependendo da quantidade de luz disponível. Nas áreas raleadas, portanto, a quantidade de plântulas novas é notoriamente maior que na mata primária ou pouco perturbada, enquanto que a mortalidade tende a seguir basicamente este mesmo padrão da natalidade. Da mesma forma o crescimento faz-se sentir mais vigorosamente em áreas perturbacias do que nas menos perturbadas ou não perturbadas, sempre com o comportamento semelhante entre as áreas perturbadas e entre as não perturbadas (comportamento extrínseco), sendo porém que todos os 
transectos estudados (tanto nas áreas raleadas quanto na mata) tenderam a ter mais plântulas crescendo abaixo da média do que acima desta (coinportamento intrínseco). Estas evidências mais uma vez indicam estar o comportamento da espécie mais estritamente relacionado com a luminosidade que com outros fatores ambientais os quais, entretanto, não podem ser excluídos (cf. Leite \& Rankin, 1981 c).

Com base nestes dados, é possível sugerir-se Pithecolobium racemosum como espécie viável para enriquecimento florestal das matas de terra firme sobre solo argiloso (segundo sua occrrência natural), a qual pode ser feita sob as seguintes condições: conforme a espécie de interesse, vai sendo retirada da mata a vai havendo formação de clareiras, inicialmente pequenas, as plântulas de $P$. racemosum po dem ser dispostas nestas áreas; é necessária a presença de alguns adultos da mesma espécie nestas áreas para obter-se uma fisionomia ambiental mais ou menos natural para a espécie; à medida que a clareira da mata aumenta pelo incrementc na retirada da espécie de in. teresse, há possibilidade de acompanhamento do crescimento das plântulas de $P$. racemosum visto que, conforme foi mencionado, este crescimento está na dependência direta das diferentes intensidades de luz, segundo as diferentes faixas de altura; além do enriquecimento de mata, esta espécie pode ser, no futuro, (após a regeneração da mata) economicamente utilizada, visto que a madeira pode ser usada para diversos fins (cf. Loureiro \& Silva 1968).

Embora o crescimento de $P$. racemosum tenha sido mais lento, comparado com o de outras espécies florestais, quando colocadas em áreas de piantio heterogêneo (Schmidt \& Volpato, 1972), levanta-se a hipótese de que este comportamento pode ter sido influenciado pelas condições empregadas durante o experimento (área totalmente derrubada e sombreamento parcial temporário); é possível dizer-se que exıste resposta diferente para áreas de clareiras de mata com luminosidade menor que a pleno sol e que estas conáições favorecem o crescimento das plântulas até certas faixas de tamanho. Existe portanto a possibilidade de viabilidade desta espécie para enriquecimento florestal sob condições acima mencionadas.

\section{SUMMARY}

It was found that population growth of seedlings of Pithecolobium racemosum followed an atypical inverted $\mathrm{J}$ distribution. This was explained on basis of the bienal crop size pattern and on the rapid initial growth of the seedlings. Population growth behaviour was found to be similar to that described for the majority of forest tree species. It was also shown that in primary forest conditions adults and seedlings are scarce or occasional, with high increases in frequency depending on the degree of disturbance. Seedlings growth seems to be highly correlated with light intensity, with different behaviour in the different areas amount of disturbance of the primary forest. Thus, the species can be considered as shade intolerante. The influence of different degrees of clearing on seedling survival was shown, as well as the influence of parental trees on the significant differences were found when comparing frequency, natality or mortality in areas with different degrees of disturbance. Thus it can be postulated that the behaviour of the species is independente, to a certain degree of external factors. P. racemosum is here suggested as an enrichment species for terra firme forests where the removal of trees induces formation of gaps or clearings.

\section{REFERENCIAS BIBLIOGRÁFICAS}

ALENCAR, J. da C.; ALMEIDA, R.A. \& FERNANDES, N.P. 1979 - Fenologia das espécies florestais em floresta tropical úmida de terra firme na Amazônia Central. Acta Amazonica, 9 (1): 163198.

BAUR, G.N.

1968 - The Ecological Basis of Rainforest Management. Forestry Comission of New South Wales, Australia. 499p.

DAUBERNMIRE, R.F.

1974 - Plants and Environment - A Textbook of Plant Autecology. New York. John Wiley \& Sons. 422p.

FOX, J.F.

1977 - Alternation and coexistence of tree species. Amer. Nat. III (977): 69-89.

HARPER, J.L.

1967 - A Darwinian approach to plant ecology. J. Ecol. 55 (2): 247-270.

1978 - The Population Biology of PTants. Academic Press. 
HARTSHORN, G.S.

1972 - The ecological Life History and Population Dynamics of Pentaclethra macroloba, a tropical Wet Forest Dominant and Stryphno. dendron excelsum, an Occasional Associate. University of Washington. 118p. (Tese).

HETT, J.M. \& LOUCKS, O.L.

1971 - Sugar maple (Acer saccharum Marsh.) seedling mortality. J. Ecol., 59 (2): 507-520.

JANZEN, D.H.

1967 - Synchronization of sexual reproduction of trees within the dry season in Central America. Evolution, 21 (3): 620-637.

1970 - Herbivores and the number of tree species in tropical forests. Amer. Nat., 104 (940): 501-528.

LAMB, F.B.

1966 - Mahogany of Tropical America. Its Ecology and Management. Ann. Arbor. University of Michigan. 220p.

LEITE, A.M.C. \& RANKIN, J.M.

1981a - Ecologia de Plântulas de Pithecolobium racemosum Ducke. I - Número e Distribuição dos individuos. Acta Amazonica, 11 (1)

1981b-- Ecologia de sementes de Pithecolobium racemosum Ducke. Acta Amazonica, 11 (2):

1981c - Relação Solo/Plântulas de Pitheco'obium racemosum Ducke. Acta Amazonica, 11 (3):

LOUREIRO, A.A. \& SILVA, M.F. da

1968 - Catálogo das Madeiras da Amazônia. Belém, SUDAM. V. 2, 411p.

MILES, J.

1973 - Early mortality and survival of self - sown seedlings in G!enfeshie, Inverness-shire. J. Ecol., 61 (1): 93-98.

ODUM, E.P.

1972 - Ecologia. México, Nueva Editorial Interamericana. $639 p$.
PIRES, J.M.

1976 - Aspectos Ecológicos da Floresta Amazônica. Anais do II Congresso Brasileiro de Florestas Tropicais. 65: 235-287.

RANKIN, J.M.

1972 - The influence of seed predaction on tree species abundances in two adjacent rain forest communities in Trinidad West Indies. 426p.

RICHARDS, P.W.

1952 - The Tropical Rain Forest. An Ecological Study. Cambridge. University Press. 450p.

RIDLEY, H.N.

1930 - Dispersal of Plants Throughout the World. Reeve, Ashford.

SCHIMIDT, P.B. \& VOLPATO, E.

1972 - Aspectos silviculturais de algumas espécies nativas da Amazônia. Acta Amazonica, 2 (2): 99-122.

SCHULZ, J.P.

1960 - Ecological studies on Rain Forest in North Suriname. Amsterdam, North - Holland. 267p.

SMITH, N.

1970 - Relationships between fruiting seasons and seed dispersal methods in a Neotropical Forest. Amer. Nat., 104 (935): 25-35.

VAN DER PIJL, L.

1972 - Principles of Dispersal in Higher Plants. New York, Springer - Verlag. 162p.

WHITMORE, T.C.

1975 - Tropical rain forest of the Far East. Oxford, Claredon Press. 282p.

(Aceito para publicação em $06 / 04 / 82$ ) 